\title{
Myocardial infarction in an urban population: worse long term prognosis for patients from less affluent residential areas
}

\author{
P Tydén, O Hansen, G Engström, B Hedblad, L Janzon
}

Correspondence to: Dr P Tydén, Department of Community Medicine, Unit of Epidemiology Malmö University Hospital, 205 02 Malmö, Sweden; patrik.tyden@smi.mas.lu.se

Accepted for publication 14 January 2002

\begin{abstract}
Study objective: The objective in this follow up study from the Malmö myocardial infarction register has been to assess whether long term survival following discharge after first myocardial infarction has any relation with the socioeconomic environment and to assess to what extent intra-urban differences in mortality from ischaemic heart disease can be accounted for by covariance with long term survival following discharge after acute myocardial infarction.

Design: Register based surveillance study.

Setting: Seventeen residential areas in the city of Malmö, Sweden.

Participants: The cohort contains all 2931 male and 2083 female patients with myocardial infarction who were discharged for the first time between 1986-95 from Malmö University Hospital.

Main results: During the on average 4.9 years of follow up $55 \%$ of the patients died. The sex adjusted and age adjusted all cause mortality rate/1000 patient years ranged between residential areas from 85.5 to 163.6. The area specific relative risk of death after discharge was associated with a low socioeconomic score, $r=-0.56, p=0.018$. Major risk factors for cardiovascular disease were more prevalent in areas with low socioeconomic score and low rates of survival. Of the intra-urban differences in mortality from ischaemic heart disease, $41 \%$ could be accounted for by differences with regard to the survival rate after discharge.

Conclusions: The results are compatible with the hypothesis that the socioeconomic environment plays an important part in the survival rate of patients with myocardial infarction. To assess the preventive potential, the extent to which socioeconomic circumstances covary with severity of disease, respectively with the use and compliance with secondary preventive measures, needs to be evaluated.
\end{abstract}

B etween and within countries there are marked differences in mortality in ischaemic heart disease. ${ }^{1-3}$ In a study from the city of Malmö in Sweden it was shown that between residential areas the age adjusted and sex adjusted annual mortality rate in ischaemic heart disease ranged from 286 to $446 / 100000 .{ }^{4}$ These differences could only partly be accounted for by covariance with incidence of disease and short-term case fatality rate. ${ }^{45}$ Areas with high mortality rates deviated in terms of their socioeconomic circumstances unfavourably from the city average. This association remained statistically significant after adjustment for differences between areas with regard to the prevalence of other major risk factors associated with cardiovascular disease. $^{6}$

The severity of coronary atherosclerosis, the degree of damage to the myocardium, and the use and compliance with secondary preventive measures are some of the factors known to modify the prognosis after myocardial infarction..$^{7-16}$ It has been our hypothesis that many of these prognostic markers covary with the patients' socioeconomic circumstances and that hence the prognosis would be poorer for patients from less affluent areas.

The objective in this follow up study from the Malmö myocardial infarction register ${ }^{17}$ has been to assess whether, in an urban population, long term survival following discharge after first myocardial infarction has any relation with the socioeconomic environment and to assess to what extent intra-urban differences in mortality from ischaemic heart disease can be accounted for by covariance with long term survival following discharge after acute myocardial infarction.

\section{METHODS}

\section{Retrieval of cases}

The city of Malmö, located in southern Sweden, has approximately 250000 inhabitants. Malmö University Hospital is the single referral unit for patients with acute myocardial infarction. After discharge the patients are taken care of by general practitioners and private physicians. From the hospital patient administrative register it is possible to retrieve, for each patient, name, 10 digit personal identification number, diagnosis, and dates of admittance and discharge. For patients with ICD codes 410.00-410.99 respectively 410A-410X according to the 8 th and 9th versions, this information has been transferred to the Malmö myocardial infarction register since 1972. The percentage of patients classified correctly has been estimated at $90 \%-95 \% .{ }^{18}$ Residential area at the time of the treatment occasion is available for cases from 1986 and onwards. During the time period 1986 to 1995 there were in all 2931 men, mean (SD) age 68.5 (11.5), and 2083 women, mean age 75.3 (10.7) who for the first time were discharged from Malmö University Hospital after treatment because of myocardial infarction. The $42 \%$ female patients can be accounted for by differences with regard to the population at risk-that is, an overrepresentation of women in age groups with the highest incidence of myocardial infarction. ${ }^{19}$ At least two of the following three criteria were required for diagnosis: (1) Central chest pain, lung oedema or shock. (2) ECG changes indicating acute myocardial infarction. (3) Increased serum activities of cardiac enzymes. ${ }^{17}$

Vital status on 31 December 1998 was updated by record linkage with the National Cause of Death Register. The average time of follow up was 4.9 years (ranging from one day to 13 years). Vital status was updated on all patients. 
Information regarding the underlying cause of death was at the time of this study only available for cases who died before 1997. Ischaemic heart disease was in $60 \%$ of the cases the underlying cause of death. The National Cause of Death Register supplied the information needed to calculate, for each of the residential areas, the average annual rate of mortality from ischaemic heart disease (ICD codes 410-414 according to the 8th and 9th version) during the time period 1986-1995. These estimates are based on 7922 deaths.

\section{Socioeconomic circumstances of residential areas}

Within the city there are 18 residential areas that in terms of morbidity and socioeconomic circumstances are not only very different from each other but have remained so over time. ${ }^{4021}$ The harbour area, because of the small number of people living there, has not been included in this study. A comprehensive socioeconomic score, SES, was used for the comparison of socioeconomic circumstances. For the computation of this score, which is based on information supplied by Malmö City Council and Statistics Sweden, ${ }^{22}$ we used data on the rate of migration, the percentage of residents with foreign citizenship among the ones with foreign background, the percentage of people receiving social welfare support (negative signs), and the rate of employment (positive sign). These parameters were selected in order to cover different aspects of the concept of socioeconomic deprivation in Sweden today. The four variables included in the SES were highly intercorrelated (all $r \geqslant 0.76$, all $\mathrm{p}<0.01$ ), indicating that they all reflect some aspect of socioeconomic deprivation. The area value for each of these four variables was standardised by subtracting from it the mean value for the city and dividing the difference by the standard deviation for all the 17 areas. ${ }^{23}$ The sum of these standardised values is the socioeconomic score of the residential area. This score, which has been used in several other studies, ${ }^{60} 24$ correlates with other well known measures of socioeconomic conditions, for example, mean income $(r=0.83, \mathrm{p}<0.01)$ and percentage of blue collar workers $(r=-0.70, \mathrm{p}<0.01)$.

Values on the percentage of people, who in each area were receiving social welfare support, are from 1991. The average value that year was $11 \%$, ranging from $0.8 \%$ to $28.6 \%$ between areas. Area specific rates of migration, which is the percentage that per year moves within or in/out from a residential area, is similarly based on values from that year. Between areas the percentages range from $5.9 \%$ to $22.6 \%$ with an average of $15 \%$ in Malmö. Foreign background was defined as foreign citizens, Swedish citizens who were born as foreign citizens, or children under 18 years of age with one or two foreign born parents. The percentage of residents with foreign citizenship as a proportion of all citizens with foreign background was used as a measure of the integration of immigrants. It should be emphasised, however, that this measure is influenced by a number of both social and economic circumstances. In 1992 there were $48 \%$ who met these criteria, with a range of $22.6 \%$ to $63.2 \%$ between areas. In 1991 the rate of employment, which is the percentage of all inhabitants between 20 and 64 years employed in the free labour market, was $79 \%$ in Malmö, ranging from $63.1 \%$ to $94.4 \%$ in residential areas.

Area of living remained unchanged for more than $90 \%$ of the patients who died during the follow up period.

\section{Prevalence of cardiovascular risk factors in residential areas}

The Malmö Diet and Cancer cohort ${ }^{25}$ was used to assess the area specific prevalence of smokers and of patients with hypertension, diabetes, and hypercholesterolaemia. This cohort consists of 28466 residents (11 206 men and 17260 women) aged 45-73 years who were examined at Malmö University Hospital between March 1991 and December 1996.

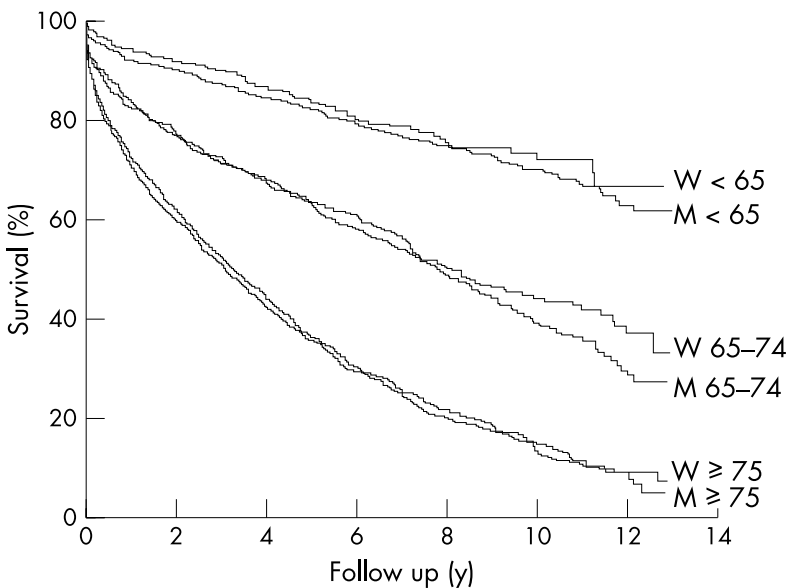

Figure 1 Kaplan-Meier curves of survival after discharge following treatment for first myocardial infarction. Men and women below 65, $65-74$, and above 74 years of age.

Mean (SD) age was 59.2 (7.0) years for men and 57.4 (7.9) for women. The number of participants per residential area ranged from 462 (area no 8) to 3285 (area no 1) and the participants/residents ratio from $27 \%$ (area no 16) to $54 \%$ (area no 8).

Smoking habits were assessed by a questionnaire. Those who confirmed regular or occasional smoking were counted as smokers.

Blood pressure was measured twice in the right arm after five minutes rest. Subjects who confirmed the use of blood pressure lowering medication, together with subjects whose systolic or diastolic blood pressure was equal to or exceeded 160 and/or $95 \mathrm{~mm} \mathrm{Hg}$, were classified as hypertensive.

The prevalence of hypercholesterolaemia is based on a subsample of 5362 subjects ( 3148 women and 2214 men) who entered the cohort between October 1991 and February 1994. Subjects who reported the use of cholesterol lowering medication and subjects whose cholesterol value exceeded 6.5 $\mathrm{mmol} / \mathrm{l}$ were considered to have hypercholesterolaemia.

Subjects who reported treatment for diabetes and subjects whose blood glucose level was $\geqslant 6.7 \mathrm{mmol} / \mathrm{l}$ were considered to have diabetes.

\section{The cardiovascular risk factor score}

These four major risk factors were used to compute an area specific cardiovascular risk factor score. This was achieved by first calculating for each area the sex adjusted and age adjusted prevalences using the equivalent average method. ${ }^{26}$ Each of these values was standardised by subtracting from it the average value for Malmö and then dividing the difference by the standard deviation for the city. ${ }^{23}$ The area score is the sum of these standardised values.

\section{Statistical methods}

Area specific rates of all cause mortaliy/1000 patients years after discharge have been adjusted for differences with regard to age distribution and sex distribution. The entire cohort of patients between 1986-95 was used as the standard population. Three age groups-that is, below $65,65-74$, and 75 and above-were used in these computations.

Area specific rates of mortality in ischaemic heart disease have similarly been adjusted for differences with regard to age and sex. The population of Malmö above 20 years of age 1986-95 was used as the standard population. The interval used for age stratification was five years.

The Kaplan-Meier method was used to illustrate survival in relation to age and sex. Cox proportional hazards analysis was 
Table 1 Age and sex adjusted all cause mortality rates after discharge in relation to the socioeconomic and the cardiovascular risk factor scores

\begin{tabular}{|c|c|c|c|c|c|c|}
\hline Residential area & $\begin{array}{l}\text { Socioeconomic } \\
\text { score }\end{array}$ & $\begin{array}{l}\text { Cardiovascular risk } \\
\text { factor score }\end{array}$ & $\begin{array}{l}\text { Number of } \\
\text { residents }\end{array}$ & Number of patients & $\begin{array}{l}\text { Dead during follow } \\
\text { up }(\mathrm{n}(\%))\end{array}$ & $\begin{array}{l}{ }^{*} \text { Mortality rates per } \\
1000 \text { patient years }\end{array}$ \\
\hline \multicolumn{7}{|l|}{ Low SES } \\
\hline 16 & -7.18 & 0.13 & 18289 & 273 & $144(52.7)$ & 140.1 \\
\hline 10 & -5.41 & -2.09 & 7691 & 110 & $44(40.0)$ & 124.4 \\
\hline 2 & -4.42 & 0.78 & 34341 & 651 & $406(62.4)$ & 159.8 \\
\hline 3 & -3.11 & 5.01 & 22734 & 600 & $362(60.3)$ & 129.1 \\
\hline 15 & -2.17 & 5.21 & 5002 & 130 & $80(61.5)$ & 163.6 \\
\hline 4 & -2.12 & 2.44 & 10597 & 233 & $119(51.1)$ & 123.8 \\
\hline \multicolumn{7}{|l|}{ Median SES } \\
\hline 13 & -1.52 & 4.52 & 9557 & 176 & $89(50.6)$ & 152.1 \\
\hline 12 & -1.46 & 2.09 & 26212 & 554 & $281(50.7)$ & 125.8 \\
\hline 9 & -0.22 & 0.07 & 12174 & 408 & $243(59.6)$ & 138.2 \\
\hline 1 & 1.54 & -1.67 & 24297 & 715 & $432(60.4)$ & 125.5 \\
\hline 5 & 2.43 & -1.76 & 11266 & 260 & $141(54.2)$ & 159.6 \\
\hline \multicolumn{7}{|l|}{ High SES } \\
\hline 14 & 2.59 & -3.90 & 10612 & 110 & $35(31.8)$ & 103.9 \\
\hline 11 & 2.87 & 1.24 & 10527 & 260 & $130(50.0)$ & 128.4 \\
\hline 6 & 3.89 & -3.83 & 11078 & 257 & $137(53.3)$ & 128.0 \\
\hline 17 & 4.44 & -3.09 & 9321 & 180 & $74(41.1)$ & 99.0 \\
\hline 7 & 4.84 & -1.97 & 4582 & 63 & $24(38.1)$ & 129.9 \\
\hline 8 & 5.01 & -3.13 & 2839 & 34 & $14(41.2)$ & 85.5 \\
\hline
\end{tabular}

used to illustrate survival rates for patients from residential areas with low, median, and high socioeconomic score after adjustment for differences with regard to age and sex. Age adjusted and sex adjusted relative risks of death after discharge in each of the 17 residential areas were calculated in a similar fashion by Cox proportional hazards analysis. Linear regression was used to illustrate to what extent these area specific relative risks of death after discharge covaried with the socioeconomic and the cardiovascular risk factor scores. The same method was used in the analysis of area specific rates of mortality in ischaemic heart disease in relation to rates of long term survival after discharge.

\section{RESULTS}

Rate of mortality after discharge in relation to age and sex

At the end of follow up 2755 of the 5014 patients were dead $(54.9 \%)$. The relative risk of dying after discharge increased by $7 \%$ per year of age (RR 1.07; 95\% CI 1.068 to 1.077). The lower mortality rate for women remained statistically significant after age adjustment (RR 0.9; 95\% CI 0.84 to 0.99) (fig 1).

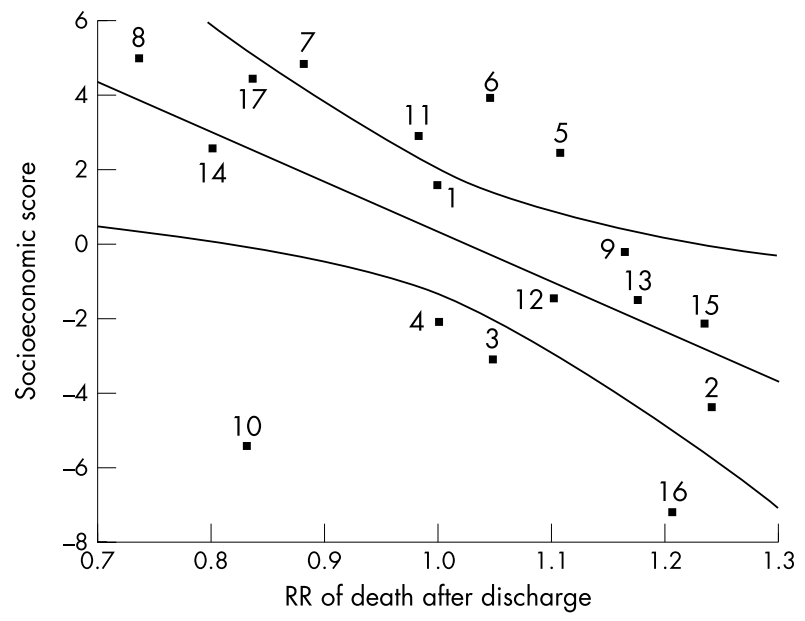

Figure 2 Relative risk of death after discharge in relation to the socioeconomic score of residential areas. Regression line with 95\% confidence intervals.
Rates of mortality after discharge in relation to the socioeconomic score

Table 1 illustrates dissimilarities between residential areas in terms of socioeconomic circumstances, the prevalence of major risk factors for cardiovascular disease, and the rates of mortality after discharge.

The age adjusted and sex adjusted all cause mortality rate following discharge after first myocardial infarction ranged between areas from 85.5 tol63.6/1000 patient years of follow up. The area specific relative risk of death after discharge covaried in a linear fashion with the socioeconomic area score, $r=-0.56, \mathrm{p}=0.018$, fig 2 . Table 2 illustrates how of each of the included socioeconomic variables covaries with the risk of death after discharge. When stratified for age $(<65(n=1275)$, 65-74 $(n=1516)$ and $>74(n=2223)$ years of age $)$ survival differences after discharge among patients living in areas with high, median, and low socioeconomic scores showed statistical significance only in the age group below 65 . The mortality rates in this age group were $22 \%$ and $40 \%$ lower for patients who came from areas with median (RR $0.78 ; 95 \% \mathrm{CI}=0.60$ to $0.99, \mathrm{p}=0.046)$ and high socioeconomic score (RR 0.60; $95 \% \mathrm{CI}=0.44$ to $0.81, \mathrm{p}<0.001$ ), fig 3 . The average follow up

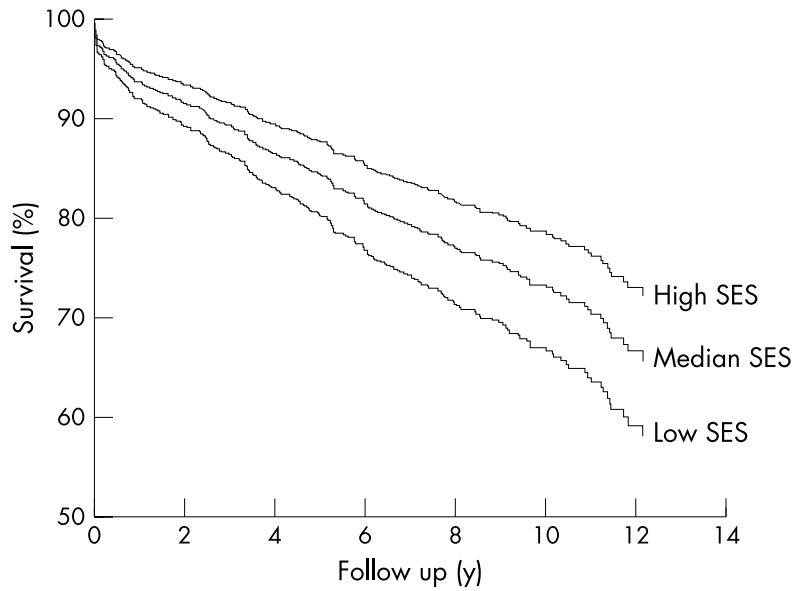

Figure 3 Survival after discharge among patients below 65 years of age from residential areas with high, median, and low socioeconomic score. Cox regression curves with adjustment for age and sex. 
Table 2 Correlation coefficients $(r)$ for the relation between socioeconomic circumstances in residential areas and the age and sex adjusted relative risks of death after discharge

\begin{tabular}{lll}
\hline & $r$ & $p$ \\
\hline Migration rate (\%) & 0.46 & 0.06 \\
Foreign citizens among foreign background (\%) & 0.56 & $<0.05$ \\
Social welfare support (\%) & 0.45 & 0.07 \\
Employment rate (\%) & -0.68 & $<0.01$ \\
Socioeconomic score (SES) & -0.56 & $<0.05$ \\
\hline
\end{tabular}

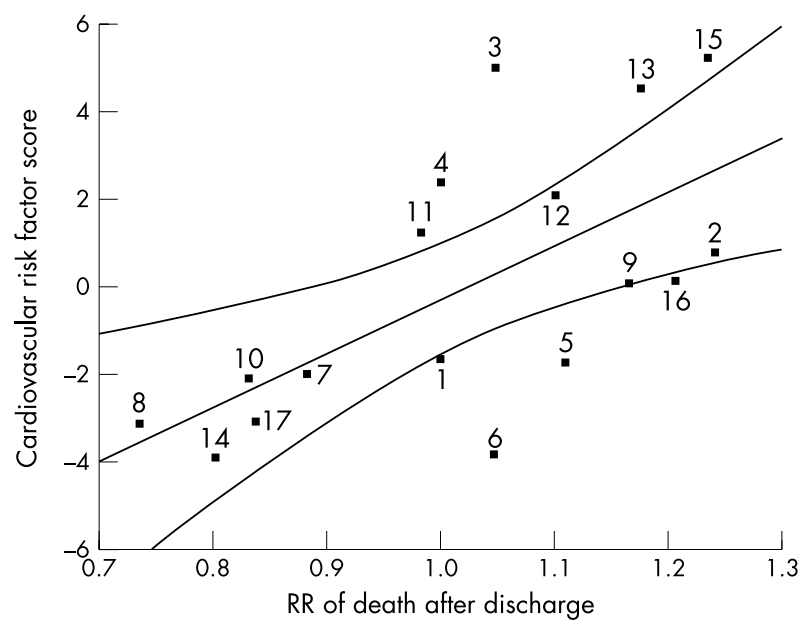

Figure 4 Relative risk of death after discharge in relation to the cardiovascular risk factor score of residential areas. Regression line with $95 \%$ confidence intervals.

time for patients from areas with high, median, and low socioeconomic scores was very similar. Only minor differences occurred when the calculations were done separately for men and women.

\section{Rates of mortality after discharge in relation to the cardiovascular risk factor score}

The age adjusted and sex adjusted area specific relative risks of death after discharge covaried in a linear fashion with the cardiovascular risk factor scores, $r=0.64, p=0.005$, fig 4 . According to this association, $41 \%$ of the intra-urban variance of mortality after discharge can be accounted for by covariance with the cardiovascular risk factor score. The corresponding value for the socioeconomic score was $32 \%$ and together the two scores accounted for $48 \%$ of the variance of mortality following discharge, table 3.

\section{Relation between area specific rate of mortality in ischaemic heart disease and survival following discharge after first myocardial infarction}

The area specific relative risks of death following discharge after first myocardial infarction covaried in a statistically sig-

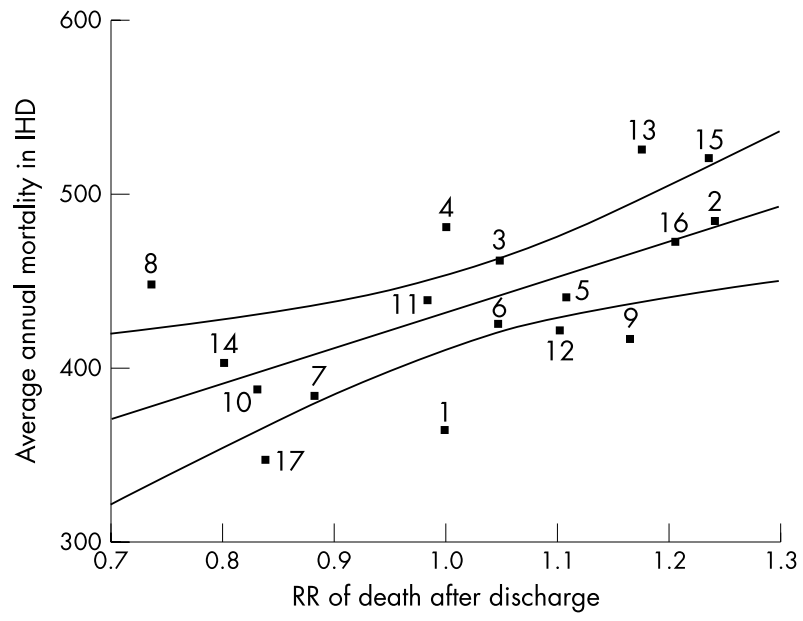

Figure 5 Age and sex adjusted rates of mortality from ischaemic heart disease per 100000 in relation to the relative risk of death after discharge. Regression line with 95\% confidence intervals.

nificant fashion with the rates of mortality in ischaemic heart disease, $r=0.64, p=0.006$, fig 5 . Forty one per cent of the intraurban variance in mortality from ischaemic heart disease can be accounted for by the variance in survival following discharge after first myocardial infarction according to this association.

\section{DISCUSSION}

Five years after discharge less than half of the patients were alive. Our results are compatible with the hypothesis that the socioeconomic environment may play an important part in the survival rate of patients with myocardial infarction and that the prognosis is poorer for patients from less affluent areas. Considering the ecological design it is however not appropriate to make any causal inferences.

Further studies are needed to explore whether the association with socioeconomic circumstances could have been confounded by covariance with other risk factors of importance for the long term prognosis, for example, the severity of coronary atherosclerosis, the degree of damage to the myocardium, the use and compliance with secondary preventive measures. Major risk factors for cardiovascular disease were more prevalent in areas with low socioeconomic score and low rates of survival. The important issue from a preventive perspective, however, is that, between groups defined in terms of residential area, there were marked differences in the age adjusted and sex adjusted rate of mortality after discharge and that these areas can be described in terms of socioeconomic circumstances and prevalence of major risk factors for cardiovascular disease. Differences in ischaemic heart disease mortality may be related to incidence, ${ }^{4}$ short-term case fatality rate, ${ }^{5}$ and survival after hospitalisation. It is our conclusion that in this city differences, in terms of long term survival after discharge, significantly contribute to the pattern of ischaemic heart disease mortality. This is an important observation in evaluating the preventive potential. An inverse relation

Table 3 Percentage of the intra-urban variance in survival after discharge accounted for by the socioeconomic and the cardiovascular risk factor scores

\begin{tabular}{llll}
\hline & $r$ & $r^{2} \times 100(\%)$ & $p$ \\
\hline Cardiovascular risk factor score & 0.64 & 41 & 0.005 \\
Socioeconomic score (SES) & -0.56 & 32 & 0.018 \\
Cardiovascular risk factor score + SES $^{*}$ & 0.69 & 48 & 0.011 \\
\hline
\end{tabular}

*Correlation between cardiovascular risk factor score and socioeconomic score: $r=-0.55, r^{2}=0.31$, $\mathrm{p}=0.021$. 


\section{Key points}

- Geographical differences in mortality from ischaemic heart disease imply a preventive potential.

- Long term survival after first myocardial infarction is in this urban population significantly worse for patients from less affluent residential areas.

- In this city differences in long term survival after first myocardial infarction significantly contribute to the geographical pattern of mortality from ischaemic heart disease.

between age and rate of survival did, as expected, dilute the influence of the socioeconomic score on the rate of survival in older age groups. The higher survival rate for patients from areas with median and high score was statistically significant only for those who were below 65 years of age. This is consistent with earlier studies showing that the relative influence of socioeconomic ${ }^{27} 28$ as well as biological ${ }^{29} 30$ risk factors on incidence and survival decreases with age. ${ }^{29} 3132$

After discharge the patients were taken care of by primary healthcare physicians. A number of trials have reported the benefits of secondary preventive measures - that is, treatment of hypertension and hyperlipidaemia, help to quit smoking, and antithrombotic treatment. Yet it seems that far from all patients receive appropriate care. ${ }^{33}$ Studies from Italy have reported a lack of standardisation with regard to risk stratification strategies after infarction. ${ }^{34}$ In studies from Sweden it has been shown that approximately $50 \%$ of patients treated for hypertension still have diastolic blood pressure exceeding the national treatment goal of $<90 \mathrm{~mm} \mathrm{Hg.}{ }^{35}$ Whether this proportion differs between groups defined in terms of their socioeconomic circumstances remains to be evaluated. The ability to quit and remain free from smoking seems on the other hand to be related to level of education and annual income. ${ }^{36}$

Differences with regard to the severity of coronary atherosclerosis and damage to the myocardium could explain why the survival curves for patients from areas with high, median, and low socioeconomic scores started to deviate already during the first year after discharge. However, as the curves of survival continued to deviate during the entire follow up period it seems reasonable to assume that rates of survival in groups defined in terms of residential area may be attributable to some extent to differences with regard to the use and compliance with secondary preventive measures.

Many of the sociodemographic circumstances associated with the rate of survival have been identified as independent risk factors for the incidence of myocardial infarction in prospective cohort studies. ${ }^{37}{ }^{38}$ According to migrant studies it seems that the sociodemographic environment in itself may influence a person's susceptibility. ${ }^{39}$ Whether these associations are applicable to patients being discharged after myocardial infarction, remains to be evaluated.

Results from both observational studies and clinical trials suggest that giving myocardial infarction patients emotional and social support can improve the survival rate. ${ }^{40-44}$ The true nature of this relation is not known. According to a mailed questionnaire survey it has been shown that, between residential areas in the city of Malmö, there are marked differences with regard to the availability of emotional support and degree of social anchorage. ${ }^{45} 46$

Some methodological issues should be considered. The follow up of patients with regard to residential area before and after infarction did not indicate that the pattern of survival could have been confounded by misclassification with regard to residential area. Residential area remained unchanged for more than $90 \%$ of the patients who died during the follow up period. All patients were treated at Malmö University Hospital, which is the only hospital for myocardial infarction and other somatic disorders in the city. The National Board of Health and Welfare has shown that the diagnosis of myocardial infarction collected via the patient administrative register is correct in $90 \%-95 \%$ of the cases. ${ }^{18}$ Previous long term follow up studies from the register have shown that the validity regarding vital status is close to $100 \% .{ }^{24}$ It thus seems unlikely that the results could be explained by geographical differences with regard to case retrieval and validation of cases and deaths.

The survival rate in our patient cohort may, compared with survival rates reported from Minnesota, ${ }^{47}$ the SPRINT registry, ${ }^{48}$ and randomised mega trials of thrombolytic therapy ${ }^{49}{ }^{50}$ seem lower than expected. However, because of differences in regard to age distribution and criteria used for inclusion and exclusion of patients, results are not readily comparable.

In this follow up of survival after myocardial infarction, 55\% of the patients were no longer alive five years later. Rate of mortality after discharge was significantly higher for patients from residential areas with inferior socioeconomic circumstances. Differences in terms of long term survival contributed to the geographical pattern of mortality from ischaemic heart disease in a significant fashion. In order to exploit the preventive potential, the extent to which socioeconomic circumstances covary with severity of disease, respectively with the use and compliance with secondary preventive measures, needs to be evaluated.

\section{Authors' affiliations}

P Tydén, G Engström, B Hedblad, L Janzon, Department of Community Medicine, Malmö University Hospital, Lund University, Malmö, Sweden

O Hansen, Department of Cardiology, Malmö University Hospital

Funding: this study was supported by grants from the Swedish Council for Social Research.

Conflicts of interest: none.

\section{REFERENCES}

1 Sans S, Kesteloot $H$, Kromhout D. The burden of cardiovascular diseases mortality in Europe. Eur Heart J 1997; 18:1213-48.

2 Nerbrand C, Svärdsudd K, Hörte LG, et al. Geographical variation of mortality from cardiovascular diseases. The project "Myocardial Infarction in mid-Sweden". Eur Heart J 1991;12:4-9.

3 Hammar N, Ahlbom A, Theorell T. Geographical differences in myocardial infarction incidence in eight Swedish counties, 1976-1981. Epidemiology 1992;3:348-55

4 Tydén $P$, Hansen $O$, Janzon L. Intra-urban variations in incidence and mortality in myocardial infarction. A study from the myocardial infarction register in the city of Malmö, Sweden. Eur Heart J 1998;19:1795-801.

5 Tydén $P$, Engström $G$, Hansen $O$, et al. Geographical pattern of female deaths from myocardial infarction in an urban population: fatal outcome out-of-hospital related to socio-economic deprivation. J Intern Med 2001;250:201-7.

6 Engström G, Berglund G, Göransson M, et al. Distribution and determinants of ischaemic heart disease in an urban population. A study from the myocardial infarction register in Malmö, Sweden. J Intern Med 2000;247:588-96

7 Volpi A, De Vita C, Franzosi MG, et al. Determinants of 6-month mortality in survivors of myocardial infarction after thrombolysis. Results of the GISSI-2 database. Circulation 1993;88:416-29.

8 Fibrinolytic Therapy Trialists (FTF) Collaborative Group: Indications for fibrinolytic therapy in suspected acute myocardial infarction: collaborative overview of early mortality and major morbidity results from all randomised trials of more than 1000 patients. Lancet 1994;343:311-22.

9 Michels KB, Yusuf S. Does PTCA in acute myocardial infarction affect mortality and reinfarction rates? A quantitative overview (meta-analysis) of the randomised clinical trials. Circulation 1995;91:476-85.

10 ISIS-2 (Second International Study of Infarct Survival) Collaborative Group. Randomised trial of intravenous streptokinase, oral aspirin, both, or neither among 17187 cases of suspected myocardial infarction: ISIS-2. Lancet 1988; ii:349-60.

11 Ades PA, Pashkow FJ, Nestor JR. Cost-effectiveness of cardiac rehabilitation after myocardial infarction. J Cardiopulm Rehabil 1997; 17:222-31

12 Yusuf S, Peto R, Lewis J, et al. Beta-blockade during and after myocardial infarction: an overview of the randomised trials. Progr Cardiovsc Dis 1985;17:335-71.

13 Pfeffer MA, Braunwald E, Moyé LA, et al. Effect of captopril on mortality and morbidity in patients with left ventricular dysfunction after myocardia infarction. N Engl J Med 1992;327:669-77. 
14 Alistair SH, Murray GD, Ball SG on behalf of the Airex Study Investigators: Follow-up study of patients randomly allocated ramipril or placebo for heart failure after myocardial infarction: AIRE Extension (AIREX) Study. Lancet 1997;349:1493-7.

15 Scandinavian Simvastatin Survival Study Group. Randomised trial of cholesterol lowering in 4444 patients with coronary heart disease: the Scandinavian Simvastatin Survival Study (4S). Lancet 1994;344:13839

16 Sacks FM, Pfeffer MA, Moye LA, et al. The effect of pravastatin on coronary events after myocardial infarction in patients with average cholesterol levels. N Engl J Med 1996;335:1001-9.

17 Hansen O, Johansson BW. Epidemiologic aspects of coronary heart disease in Malmö 1935-1988. Am J Epidemiol 1991;133:721-33.

18 The National Board of Health and Welfare. Värdering av diagnoskvaliteten för akut hiärtinfarkt $i$ tre svenska län 1995. Artikelnr 1997-84-8. Stockholm: 1997

19 Mosca L, Manson JE, Sutherland SE, et al. Cardiovascular disease in women. A statement for healthcare professionals from the American Heart Association. Circulation 1997;96:2468-82.

20 Engström G Jerntorp I, Pessah-Rasmussen H, et al. Geographic distribution of stroke incidence within an urban population: relations to socieconomic circumstances and prevalence of cardiovascular risk factors. Stroke $2001 ; 32: 1098-103$.

21 Manjer J, Berglund G, Bondesson L, et al. Intra-urban differences in breast cancer mortality: a study from the city of Malmö in Sweden. J Epidemiol Community Health 2000;54:279-85

22 The Unit of Planning and Statistics. Områdesfakta för Malmö 1991-1996. Malmö: Malmö City Council, 1991-1996.

23 Woodward M. Small area statistics as markers for personal social status in the Scottish heart health study. J Epidemiol Community Health 1996;50:570-6.

24 Engström G, Göransson M, Hansen O, et al. Trends in long-term survival after myocardial infarction: less favourable patterns for patients from deprived areas. J Intern Med 2000;248:425-34.

25 Berglund G, Elmståhl S, Janzon, et al. Design and feasibility. J Intern Med 1993;233:45-51.

26 Merlo J, Ranstam J, Råstam L, et al. Age standardisation of drug utilisation: comparisons of different methods using cardiovascular drug data from Sweden and Spain. Eur J Clin Pharmacol 1994;46:393-8.

27 Peltonen $M$, Rosén $M$, Lundberg V, et al. Social patterning of myocardial infarction and stroke in Sweden: incidence and survival. Am J Epidemiol 2000;151:283-92.

28 Kunst AE, Mackenbach JP. The size of mortality differences associated with educational level in nine industrialized countries. Am J Public Health 1994:84:932-7.

29 Anderson KM, Wilson P, Odell PM, et al. An updated coronary risk profile. A statement for health professionals. Circulation 1991;83:356-62

30 Dawber TR. The Framingham study: the epidemiology of atherosclerotic disease. Cambridge, MA: Harward University Press, 1980.

31 Wannamethee G, Whincup P, Shaper AG, et al. Factors determining case fatality in myocardial infarction "Who dies in a heart attack?" $\mathrm{Br}$ Heart J 1995;74:324-31.

32 Niölstad I, Arnesen E. Preinfarction blood pressure and smoking are determinants for fatal outcome of myocardial infarction. Arch Intern Med 1998; 158:1326-32

33 Euroaspire Study Group. Euroaspire. A European Society of Cardiology survey of secondary prevention of coronary heart disease: Principal results. Eur Heart J 1997; 18:1569-82.
34 Maggioni AP, Tavazzi L, Fabbri G, et al. Epidemiology of post-infarction risk stratification strategies in a country with low volume of revascularisation procedures. The GISSI Prognosis Registry. Eur Heart J 1998; 19:1784-94.

35 Nilsson P, Andersson DKG, Andersson P-E, et al. Cardiovascular risk factors in treated hypertensives - a nationwide, cross-sectional study in Sweden. J Intern Med 1993;233:239-45.

36 Engström G, Tydén P, Berglund $G$, et al. Incidence of myocardial infarction in women. A cohort study of risk factors and modifiers of effect. J Epidemiol Community Health 2000;54:104-7.

37 Suadicani P, Hein HO, Gyntelberg F. Serum validated tobacco use and social inequalities in risk of ischemic heart disease. Int J Epidemiol 1994;23:293-300

38 Holme I, Helgeland A, Hjermann I, et al. Four year mortality by some socioeconomic indicators: the Oslo study. J Epidemiol Community Health 1980;34:48-52

39 Marmot MG, Syme SL, Kagan A, et al. Epidemiologic studies of coronary heart disease and stroke in Japanese men living in Japan, Hawaii, and California: prevalence of coronary and hypertensive heart disease and associated risk factors. Am J Epidemiol 1975;102:514-25.

40 Carinci F, Nicolucci A, Ciampi A, et al. Role of interactions between psychological and clinical factors in determining 6-month mortality among patients with acute myocardial infarction. Eur Heart J 1997; 18:835-45.

41 Thomas SA, Friedmann E, Wimbush F, et al. Psychological factors and survival in the cardiac arrhythmia trial (CAST): a reexamination. Am J Crit Care 1997;6:1 16-26.

42 Kawachi I, Colditz GA, Ascherio A, et al. A prospective study of social networks in relation to total mortality and cardiovascular disease in men in the USA. J Epidemiol Community Health 1996;50:245-51.

43 Friedmann E, Thomas SA. Pet ownership, social support, and one-year survival after acute myocardial infarction in the Cardiac Arrhythmia Suppression Trial (CAST). Am J Cardiol 1995;76:1213-17.

44 Berkman LF, Leo-Summers L, Horwitz RI. Emotional support and survival after myocardial infarction. A prospective, population-based study of the elderly. Ann Intern Med 1992;117:1003-9.

45 Nilsson Å, Hanson BS, Isacsson S-O. Public Health Report-Malmö County 1991 (Folkhälsorapport - Malmö kommun 1991). Malmö: Department of Community Medicine, Malmö University Hospital, 1991.

46 Lindström M, Bexell A, Hanson BS, et al. Public Health Report-Malmö County 1994 (Folkhälsorapport - Malmö kommun 1994). Malmö: Department of Community Medicine, Malmö University Hospital, 1994.

47 Orencia A, Bailey K, Yawn BP, et al. Effect of gender on long-term outcome of angina pectoris and myocardial infarction/sudden unexpected death. JAMA 1993;269:2392-7.

48 Benderly M, Behar S, Reicher-Reiss H, et al for the SPRINT study Group. Long-term prognosis of women after myocardial infarction. Am J Epidemiol 1997; 146:153-60.

49 Baigent C, Collins R, Appleby P, et al. ISIS-2: 10 year survival among patients with suspected acute myocardial infarction in randomised comparison of intravenous streptokinase, oral aspirin, both, or neither The ISIS-2 (Second International Study of Infarct Survival) Collaborative Group. BMV 1998:316:1337-43.

50 Franzosi MG, Santoro E, De Vita C, et al. Ten-year follow up of the first megatrial testing thrombolytic therapy in patients with acute myocardial infarction. Circulation 1998;98:2659-65. 